\title{
Editorial
}

\section{Corporate Social Responsibility Within the Organization}

Corporate Reputation Review (2009) 12, 83-86. doi:10.1057/crr.2009.13

\section{INTRODUCTION}

As reflected by theoretical debates in academic journals and books, as well as practitioner discussions, corporate social responsibility (CSR) ranks high on research agendas. Whether it is in response to external pressures - from government, civil society, or the public - or driven by an internal belief in the economic benefits of responsible business practices, many companies are starting to take concrete steps to deal with social and environmental issues. Supposedly, CSR is the right thing to do, and leading organizations see well-managed CSR as a way to improve their performance and create new business opportunities.

The debate about whether existing management models need to be revisited and adapted to allow for the integration of CSR concerns remains ongoing. Integrating social and environmental concerns progressively into a company's daily operations and its interactions with stakeholder groups demands a new model of economic success, based on a company's ability to interact directly and dynamically with its various stakeholder groups. However, such an integration is a real challenge. How can companies develop a more proactive CSR strategy that leverages their competitive advantage and leads to enhanced social and environmental performances? Some companies have created a department dedicated to CSR, but research indicates that such companies develop fewer capabilities than do companies that integrate environmental concerns at the corporate level, because in the latter, CSR becomes integrated across all levels of the company as part of its overall strategy (Banerjee, 1998, 2001). Departments focused solely on CSR are subject to the criticism that they make social and environmental issues appear additional to the company's core business - an added element with no particular relevance to the company's mainstream operations, such as strategy, marketing, finance and human resources.

Becoming socially and environmentally responsible is a very complex task because neither social nor environmental problems can be laid out as a series of neatly packaged alternatives. Moreover, CSR literature provides only limited guidance about how to integrate various initiatives into a sound program that can address a wide range of CSR aspects. Studies usually focus on implementing a few aspects of CSR, and little research pertains to the concrete and systematic implementation of CSR within an organization. This special issue of Corporate Reputation Review, therefore, attempts to address how managers frame and enact CSR across their companies' different business practices, functions and markets, and seeks to understand how companies can work to integrate CSR into the mainstream of their everyday business theory and practices.

\section{STRUCTURE AND CONTENT OF THE SPECIAL ISSUE}

Despite its wide diffusion and potential relevance for employee management (Brammer
Corporate Reputation Review Vol. 12, No. 2, pp. 83-86 (c) 2009 Palgrave Macmillan, 1363-3589 
et al., 2007), CSR remains under investigated in both organizational behavior and human resource management research (Aguilera et al., 2007). Yet, employees often emerge as the most important stakeholder group toward whom the corporation must exercise its social responsibility (D'Humières and Chauveau, 2001). The first two articles of this special issue address this literature gap by investigating the role of employees as internal stakeholders in the implementation of accountable CSR mandates.

The first article, 'Employee Involvement in Implementing CSR in Cross-Sector Social Partnerships,' by May Seitanidi, discusses the role of employees in delivering accountable CSR implementation during the process of forming, implementing and delivering outcomes in non-profit business partnerships. The article builds an in-depth partnership case study between Rio Tinto and Earthwatch to develop a model for accountable CSR implementation. The article offers suggestions for how to enhance internal accountability through a proactive involvement of employees at all stages of the development of the non-profit business partnerships. This includes, for example, participation of employees in the selection of business partners; programs that help employees to better in organizational change; and development of personal non-profit business relationships that help to facilitate change at the individual level.

In the second article, 'Employee Participation in CSR and Corporate Identity: Insights from a Disaster Response Program in the Asia-Pacific,' Mark Chong examines how corporate identity influences - or is influenced by - employee participation in CSR programs. By considering DHL AsiaPacific's disaster-management response to the 2004 Asian tsunami, this article explores the importance of aligning CSR implementation with corporate identity to enhance employees' commitment to the organization and ensure the success of the CSR programs.
The article also highlights the crucial role of internal communication that projects corporate identity to employees. In turn, employees' CSR participation galvanizes their experience of the company's corporate identity, forming a self-reinforcing loop.

Also of interest for managers is the role of the marketing function in the implementation of a CSR strategy. In response to changing employee demands, rising customer expectations and investor interest in social criteria, many organizations are coming to realize that marketing extends beyond an organization and its customers (Kotler and Keller, 2008. For years, marketing literature has stressed the need to understand the linkage among ethics, social responsibility, strategy, business and marketing (Ferrell and Gresham, 1985).

In that respect, the third article by Adam Lindgreen, Valérie Swaen and Wesley Johnston investigates 'The Supporting Function of Marketing in Corporate Social Responsibility.' Using a sample of 441 US companies, the authors offer insights into the role that relational marketing practices might play in the design and implementation of CSR. Because stakeholders must understand the realities of business, companies must understand how stakeholders perceive the business and remain open to improvement and change - a relational marketing perspective. However, a transactional perspective of marketing remains useful for developing certain types of CSR activities related to formal stakeholders, such as customers, suppliers and investors. Thus, different marketing practices can combine to encourage CSR activities, depending on the types of issues and stakeholders. Finally, this article helps make the case for CSR by showing a positive link between environmental and philanthropic activities and organizational performance.

Min-Young Lee, Ann Fairhurst and Scarlett Wesley, in 'Corporate Social Responsibility: A Review of the Top 100 Retailers,' address 
the existing knowledge gap about the US retail industry's commitment and attention to socially responsible behaviors. Specifically, as its framework, their study reviews corporate retailers' Web pages and their discussion of CSR principles and processes. The study's findings suggest varied attention to CSR according to retail identity; of the various types of retailers, grocery stores and restaurants communicate most about CSR on their corporate Web sites. Furthermore, many retail companies fail to mention CSR on their Web sites, even though earlier research shows that most Fortune 500 companies employ their sites to promote some aspects of CSR.

Evidence also suggests growing interest in corporate responses to CSR expectations, particularly in terms of how CSR issues might be incorporated into organizational practices, such as branding, cause-related marketing and reputational risk management. For example, Fair Trade coffee plays a prominent role in the consumer movement to encourage socially responsible consumption; however, the extent of customers' understanding of, preference for and willingness to pay for socially responsible coffee remains poorly understood, and roasters are unsure of the message strategy to use to promote their efforts in advertisements. The fifth article, 'Taste Great or More Fulfilling: The Effect of Brand Reputation on Consumer Social Responsibility Advertising for Fair Trade Coffee,' by Carl Obermiller, Chauncey Burke, Gareth Green and Erin Talbott, examines the comprehension and preference of consumers, as well as the price they will pay, for Fair Trade coffee; it also tests the effectiveness of advertising socially responsible consumption as a prime benefit. The authors find that consumers believe that Fair Trade coffee is inferior in taste, but this belief does not affect their actual taste perceptions; consumers also are willing to pay a premium price for Fair Trade coffee, but they have a poor understanding of the mean- ing of the Fair Trade label. More important, this research shows that a socially responsible consumption message is more effective than a superior taste message for company brands that have a high-quality reputation, but for unknown companies, a superior taste message remains more effective than a socially responsible consumption message.

Finally, Rafael Currás Pérez adds significant knowledge to the field of CSR in the sixth article, 'Effects of Perceived Identity Based on Corporate Social Responsibility: The Role of Consumer Identification with the Company,' by focusing on how consumer identification with a company may mediate the effect of CSR-based corporate identity on consumer behavior. The study deals with the direct and indirect influences of identification with a socially responsible company on purchase intentions through two affective variables - attitude and affective commitment to the company. The empirical study tests the proposed model and reveals that CSR-based consumer-company identification influences purchase intentions through the mediating role of company attitude and company commitment.

\section{OTHER RESEARCH FIELDS}

As the selected articles indicate, the issues surrounding CSR within organizations constitute a rich area of inquiry. Thus, this special issue offers some preliminary insights that may help managers actively integrate their stakeholders into the CSR process and communicate their CSR involvement to various stakeholder groups.

Finally, this special issue should lead to additional research on CSR within organizations. Issues that remain to be investigated include comprehensive frameworks that address CSR within the organization; managing the CSR architecture in organizations; organizational changes necessary for embracing CSR; the organizational capabilities necessary for building, maintaining and developing CSR; and the relationship between 
CSR activities and the organization's functional activities (eg, human resources, marketing and public relations). Furthermore, more in-depth, company-specific research could bring to the surface valuable insights that might challenge some conventional thinking on the subject. Other research issues include ways to overcome resistance to change (incremental or transformational); analyses of the concrete and systematic implementation of CSR within an organization; best practices (in relation to the previous topics); analyses of how and why CSR might affect employees' attitudes and behaviors; analyses of the impact of CSR implementation on corporate reputation and organizational performance; and, finally, ways to develop the stakeholder orientation necessary for maintaining and developing CSR.

\section{References}

Aguilera, R., Rupp, D.E., Williams, C.A. and Ganapathi, J. (2007) 'Putting the s back in corporate social responsibility: A multilevel theory of social change in organizations', Academy of Management Review, 32(3), 836-863.

Banerjee, S.B. (1998) 'Corporate environmentalism: Perspectives from organizational learning', Management Learning, 29(2), 147-164.
Banerjee, S.B. (2001) 'Corporate environmentalism: The construct and its measurement', Journal of Business Research, 55(3), 177-191.

Brammer, S., Millington, A. and Rayton, B. (2007) 'The contribution of corporate social responsibility to organizational commitment', International Journal of Human Resource Management, 18(10), 1701-1719.

D'Humières, P. and Chauveau, A. (2001) Les Pionniers de l'Entreprise Responsible, Edition d'Organisation, Paris.

Ferrell, O.C. and Gresham, L.G. (1985) 'A contingency framework for understanding ethical decision making in marketing', Journal of Marketing, 49, 87-96.

Kotler, P. and Keller, K.L. (2008) Marketing Management, 13th edn, Prentice Hall, London.

\section{Adam Lindgreen \\ University of Hull Business School, Hull, UK}

Valérie Swaen Université catholique de Louvain, Place des Doyens 1, Louvain-la-Neuve, Belgium

François Maon

Université catholique de Louvain, Place des Doyens 1, Louvain-la-Neuve, Belgium 